\title{
Clinicopathological features and post-resection outcomes of inflammatory pseudotumor of the liver
}

\author{
Kibong Oh ${ }^{1}$, Shin Hwang ${ }^{2}$, Chul-Soo Ahn ${ }^{2}$, Ki-Hun Kim², Deok-Bog Moon ${ }^{2}$, \\ Tae-Yong $\mathrm{Ha}^{2}$, Gi-Won Song ${ }^{2}$, Dong-Hwan Jung $^{2}$, and Seung-Mo Hong ${ }^{3}$ \\ ${ }^{1}$ Department of Surgery, Anyang SAM Hospital, Anyang, Departments of ${ }^{2}$ Surgery and ${ }^{3}$ Pathology, \\ Asan Medical Center, University of Ulsan College of Medicine, Seoul, Korea
}

\begin{abstract}
Backgrounds/Aims: Hepatic inflammatory pseudotumor (HIPT) is a rare disease characterized by chronic infiltration of inflammatory cells and area of fibrosis. The objective of this retrospective observational study was to investigate clinicopathological features and outcomes of patients who underwent hepatic resection (HR) for HIPT. Methods: From 2009 to 2018, seven patients with HIPT underwent HR, accounting for $0.06 \%$ of 11,979 adults who underwent HR at our center. Results: These seven patients included five men and two women. Their mean age was $62.3 \pm 11.6$ years. In four patients with hepatitis B virus (HBV)-associated liver cirrhosis or chronic hepatitis, liver masses were suspected of hepatocellular carcinoma (HCC) or combined HCC-cholangiocarcinoma based on imaging studies. In three patients without HBV infection, two patients were suspected of $\mathrm{HCC}$, for whom liver biopsy was not performed. One patient was suspected of liver abscess or HIPT, for whom percutaneous liver biopsy was performed and the mass was diagnosed with HIPT. However, this patient underwent HR owing to abdominal pain. No patient presented with abnormally elevated levels of alpha-fetoprotein, protein induced by vitamin K absence or antagonist-II, or CA19-9. During a mean follow-up period of $76.4 \pm 34.8$ months, no patient experienced recurrence of HIPT. Conclusions: HIPT, a rare form of liver disease, is often misdiagnosed as malignant liver tumor. Active histological diagnosis is warranted for patients with suspected HIPT to avoid unnecessary operation. HR can be indicated in case of diagnostic ambiguity of HIPT or under a clinical diagnosis of malignant liver tumor. (Ann Hepatobiliary Pancreat Surg 2021;25:34-38)
\end{abstract}

Key Words: Abscess; Inflammation; Liver mass; Benign disease; Hepatocellular carcinoma

\section{INTRODUCTION}

Inflammatory pseudotumor (IPT) is a rare disease characterized by chronic infiltration of inflammatory cells and area of fibrosis. ${ }^{1}$ It is also known as inflammatory myofibroblastic tumor or plasma cell granuloma. ${ }^{2}$ Its etiology is uncertain, although infectious condition, autoimmune phenomenon, and systemic inflammatory response syndrome have been suggested to play roles in its pathogenesis. ${ }^{2-5}$ Recently, IPTs are more frequently recognized than before probably due to frequent abdominal imaging studies.

Despite recent development of radiologic imaging studies, it is still difficult to differentiate hepatic inflammatory pseudotumor (HIPT) from malignant tumors (such as hepatocellular carcinoma $[\mathrm{HCC}]$, intrahepatic cholangiocarci- noma [ICC], and metastatic cancer ${ }^{6,7}$ ) and liver abscess showing incomplete liquefaction and granulation. ${ }^{8,9}$ Treatment for HIPT has not been established yet. ${ }^{9-12}$ Due to its diagnostic ambiguity, some patients undergo surgical resection and other patients are managed with antibiotics, nonsteroidal anti-inflammatory drugs, or no medication. ${ }^{2,7,9,13-15}$ The objective of this study was to investigate clinicopathological features and outcomes of patients who underwent hepatic resection (HR) for HIPT.

\section{MATERIALS AND METHODS}

\section{Patient selection}

Liver resection database at our institution was extensively searched to identify patients diagnosed with HIPT.

Received: September 13, 2020; Revised: September 18, 2020; Accepted: September 20, 2020

Corresponding author: Shin Hwang

Department of Surgery, Asan Medical Center, University of Ulsan College of Medicine, 88 Olympic-ro 43-gil, Songpa-gu, Seoul 05505, Korea Tel: +82-2-3010-3930, Fax: +82-2-3010-6701, E-mail: shwang@amc.seoul.kr

Copyright (C) 2021 by The Korean Association of Hepato-Biliary-Pancreatic Surgery

This is an Open Access article distributed under the terms of the Creative Commons Attribution Non-Commercial License (http://creativecommons.org/ licenses/by-nc/4.0) which permits unrestricted non-commercial use, distribution, and reproduction in any medium, provided the original work is properly cited. Annals of Hepato-Biliary-Pancreatic Surgery • pISSN: 2508-5778 - elSSN: 2508-5859 
Of 11,976 patients who underwent HR for various indications from January 2009 to December 2018, ${ }^{14}$ seven $(0.06 \%)$ were pathologically diagnosed with HIPT using resected liver specimens. Medical records of these patients were retrospectively reviewed. This study protocol was approved by the Institutional Review Board (IRB) of our institution. The requirement for informed consent was waived due to the retrospective nature of this study. This study was performed in accordance with ethical guidelines of the World Medical Association Declaration of Helsinki 2013. Patients were followed up until August 2020 based on medical record review with the assistance of the National Health Insurance Service.

\section{Preoperative evaluation, surgical procedures, and postoperative follow-up}

Routine preoperative evaluation was performed for primary liver tumors as described previously. ${ }^{16}$ In general, patients who underwent HR for benign diseases were followed up every 6 months during 3 years after surgery and every 1-2 years thereafter as part of routine health screening.

\section{Statistical analysis}

Numerical data are presented as means and standard deviations. All statistical analyses were performed using
SPSS version 22 (IBM, New York, NY, USA).

\section{RESULTS}

\section{Patient demographics and preoperative diagnosis}

Clinicopathological features of seven patients with HIPT are described in Table 1. These seven patients included five men and two women. Their mean age was $62.3 \pm 11.6$ years. Four $(57.1 \%)$ patients were positive for hepatitis B virus (HBV) infection. However, none of them was positive for hepatitis $\mathrm{C}$ virus infection or had alcoholic liver disease. Liver lesions were detected during routine health screening or HBV-associated HCC screening in five patients and during general examination for abdominal pain in two patients.

In four patients with $\mathrm{HBV}$-associated liver cirrhosis or chronic hepatitis, liver masses were suspected of HCC or combined HCC-cholangiocarcinoma on imaging studies (Fig. 1). One of them (Case No. 4) underwent percutaneous liver biopsy; however, no mass was identified. In three patients without HBV infection, two patients were suspected of HCC, thus liver biopsy was not performed. In contrast, one patient (Case No. 1) was suspected of liver abscess, ICC or HIPT. Percutaneous liver biopsy was performed for this patient and the mass was diagnosed

Table 1. Profiles of seven patients diagnosed with inflammatory pseudotumor of the liver

\begin{tabular}{|c|c|c|c|c|c|c|c|c|c|c|c|c|c|}
\hline $\begin{array}{l}\text { Case } \\
\text { No. }\end{array}$ & Sex & $\begin{array}{l}\text { Age } \\
\text { (yrs) }\end{array}$ & $\begin{array}{l}\text { HBV } \\
\text { infec- } \\
\text { tion }\end{array}$ & $\begin{array}{l}\text { Clinical } \\
\text { diagnosis }\end{array}$ & $\begin{array}{c}\text { Liver } \\
\text { biopsy }\end{array}$ & $\begin{array}{l}\text { Preoper- } \\
\text { ative } \\
\text { AFP } \\
(\mathrm{ng} / \mathrm{ml})\end{array}$ & $\begin{array}{l}\text { Preoper- } \\
\text { ative } \\
\text { PIVKA- } \\
\text { II } \\
(\mathrm{mAU} / \\
\mathrm{ml})\end{array}$ & $\begin{array}{l}\text { Preoper- } \\
\text { ative } \\
\text { CA19-9 } \\
\text { (ng/ml) }\end{array}$ & $\begin{array}{l}\text { Extent } \\
\text { of } \\
\text { hepatic } \\
\text { resec- } \\
\text { tion }\end{array}$ & $\begin{array}{l}\text { Tumor } \\
\text { size } \\
(\mathrm{cm})\end{array}$ & $\begin{array}{c}\text { Tumor } \\
\text { num- } \\
\text { ber }\end{array}$ & $\begin{array}{l}\text { Fol- } \\
\text { low-up } \\
\text { period } \\
(\mathrm{mos})\end{array}$ & $\begin{array}{c}\text { Survival } \\
\text { status }\end{array}$ \\
\hline 1 & $\mathrm{~F}$ & 83 & No & $\begin{array}{l}\text { Abscess, } \\
\text { HIPT, ICC }\end{array}$ & HIPT & 2.5 & 27 & 15.7 & LL & 3.5 & 1 & 123 & Alive \\
\hline 2 & M & 70 & No & $\mathrm{HCC}$ & ND & 3.2 & 17 & ND & RL & 5.0 & 1 & 94 & Alive \\
\hline 3 & $\mathrm{~F}$ & 56 & Yes & $\begin{array}{l}\mathrm{HCC}, \\
\text { cHCC-CC }\end{array}$ & ND & 3.2 & 27 & 2 & LLS & 2.3 & 1 & 91 & Alive \\
\hline 4 & M & 46 & Yes & $\mathrm{HCC}$ & No mass & 4.7 & 22 & ND & RAS & 0.7 & 1 & 89 & Alive \\
\hline 5 & M & 60 & No & $\mathrm{HCC}$ & ND & 2.1 & 32 & 2.8 & RL & 5.5 & 1 & 79 & Alive \\
\hline 6 & M & 61 & Yes & $\mathrm{HCC}$ & ND & 2 & 19 & 13.6 & LMS & 1.5 & 1 & 33 & Alive \\
\hline 7 & M & 60 & Yes & $\begin{array}{l}\text { Metastasis, } \\
\text { HCC }\end{array}$ & ND & 4.8 & 36 & 10.4 & LLS & $2.5,1.4$ & 2 & 26 & Alive \\
\hline
\end{tabular}

HBV, hepatitis B virus; HIPT, hepatic inflammatory pseudotumor; ICC, intrahepatic cholangiocarcinoma; HCC, hepatocellular carcinoma; cHCC-CC, combined hepatocellular carcinoma-cholangiocarcinoma; ND, not done; AFP, alpha-fetoprotein; PIVKA-II, protein induced by Vitamin K absence or antagonist-II; CA19-9, carbohydrate antigen 19-9; LL, left lobectomy; RL, right lobectomy; LLS, left lateral sectionectomy; RAS, right anterior sectionectomy; LMS, left medial sectionectomy 


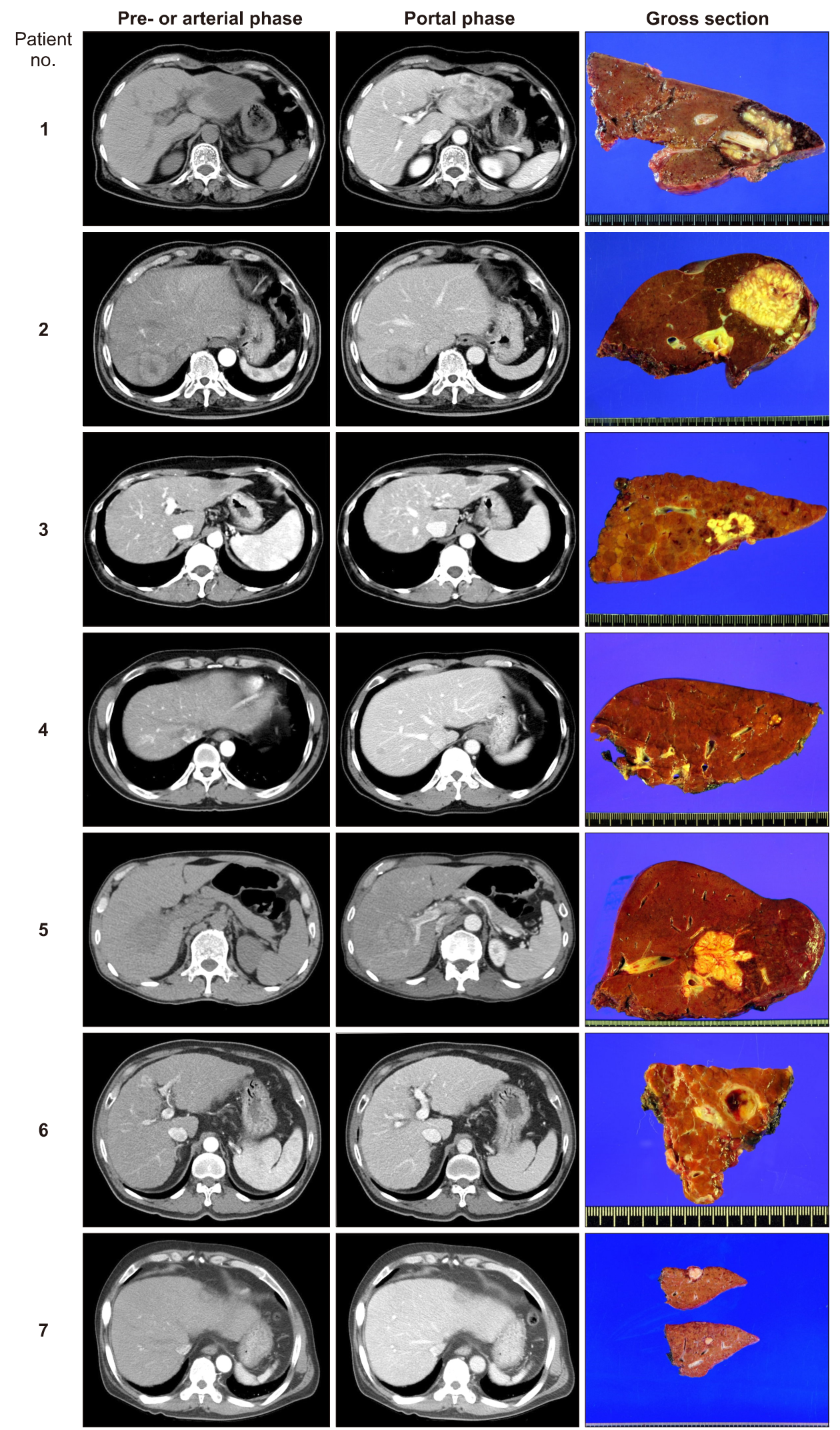

Fig. 1. Preoperative computed tomography findings and gross photographs of surgical specimens obtained after initial hepatectomy. Number denotes Case number. with HIPT. However, the patient underwent HR instead of observation owing to persistence of abdominal pain.

Mean preoperative serum concentrations of alpha-feto- protein (AFP; $3.2 \pm 1.2 \mathrm{ng} / \mathrm{ml}$; reference: $7.5 \mathrm{ng} / \mathrm{ml}$ ), protein induced by vitamin $\mathrm{K}$ absence or antagonist-II (PIVKA-II; 25.7 $\pm 6.9 \mathrm{mAU} / \mathrm{ml}$; reference: $40 \mathrm{mAU} / \mathrm{ml}$ ), and carbohy- 
drate antigen 19-9 (CA19-9; 8.9 $6.2 \mathrm{ng} / \mathrm{ml}$; reference: 37 $\mathrm{ng} / \mathrm{ml}$ ) were within normal ranges. None of these patients had abnormal levels of these tumor markers.

\section{Outcomes after hepatic resection}

The extent of HR was decided based on tumor location and size. Two patients underwent right hepatectomy. One each underwent right anterior sectionectomy, left hepatectomy, and left medial sectionectomy. Two underwent left lateral sectionectomy. All patients recovered uneventfully from HR without any major complications. During a mean follow-up period of $76.4 \pm 34.8$ months, no patient experienced recurrence of HIPT. Currently, all seven patients are alive and doing well.

\section{DISCUSSION}

HIPT is a rare disease. It does not show specific symptoms, laboratory findings, or radiologic features. A Korean multicenter study ${ }^{9}$ has suggested that dynamic computed tomography (CT) and gadolinium (Gd)-enhanced magnetic resonance imaging (MRI) can provide clues to the diagnosis of HIPT in patients with liver mass and normal tumor marker levels. Because there is not pathognomonic finding, clinical suspicion and subsequent histological diagnosis are necessary to make accurate diagnosis for HIPT. In this study reflecting the reality, the majority of liver masses were clinically diagnosed with HCC. Thus, percutaneous liver biopsy was performed in only 2 of 7 patients.

The etiology of HIPT is unknown yet, although inflammatory pattern of pathology and its associated laboratory findings have been suggested to have possible association with underlying infection via hepatobiliary tract in several studies. ${ }^{2,5}$ Some studies have shown that $68 \%-80 \%$ of patients have hepatobiliary tract disease. ${ }^{14,17-20}$ Abdominal pain, fever, and elevated inflammatory markers (including erythrocyte sedimentation rate, C-reactive protein, and leukocyte count) are common in HIPT cases. ${ }^{2,9,14,17,18}$ These findings suggest the association of an underlying infectious condition with HIPT.

HIPT presents as a large solitary mass. It occurs predominantly in the right lobe, although multicentricity has been also described. ${ }^{2,17,21-23}$ A Korean multicenter has also shown that the mean size of mass is $4.4 \mathrm{~cm}$ and that the majority of patients have a single tumor with right liver predominance. ${ }^{9}$ Results of the present study showed that a solitary mass of variable size without locational predominance was the common finding.

In the literature, HIPT has shown inconsistent appearance on radiologic studies without specific image findings. ${ }^{2,8,9,17}$ The majority of HIPT patients show poorly defined hypoattenuating lesion in pre-contrast CT, poorly defined peripheral enhancement at arterial phase, and poorly defined hyperattenuating lesions with internal hypoattenuating area at equilibrium phase during dynamic CT imaging. Pre-contrast MRI shows low signal intensity lesion at T1weighted image and relatively homogenous high signal intensity lesion at T2-weighted image. Gd-enhanced MRI shows poorly defined peripheral rim-like enhancement at the arterial phase. However, similar enhancement patterns during $\mathrm{CT}$ or MRI can be observed in other lesions such as atypical HCC, ICC, metastatic tumors and abscess. ${ }^{6,7,10}$ Because of such ambiguity in imaging diagnosis, histological diagnosis is essential to diagnose HIPT accurately.

It is known that the clinical course and prognosis of HIPT are favorable with conservative treatment. 2,5,8, $, 14,17,23$ In the present study, no recurrence occurred during a mean follow-up period of $76.4 \pm 34.8$ months. In seven patients of this study, six received HR under the clinical diagnosis of liver malignancy. In contrast, one patient received HR instead of observation despite preoperative pathological diagnosis of HIPT. The primary reason to choose HR in this patient was the presence of abdominal pain. If HIPT is pathologically diagnosed in the percutaneous liver biopsy, it is reasonable to manage it with supportive care or observation for a while. If the mass grows or other abnormal findings are found, more aggressive treatment including surgical resection should be taken into account.

This study has several limitations, including its retrospective design and inclusion of a small number of patients treated at a single center. Multi-center studies are needed in the future to evaluate characteristics of this very rare disease.

In conclusion, HIPT is a rare form of liver disease that is often misdiagnosed as malignant liver tumor. Active histological diagnosis is warranted for patients with suspected HIPT to avoid unnecessary operation. HR can be indicated in case of diagnostic ambiguity of HIPT or under a clinical diagnosis of malignant liver tumor. 


\section{CONFLICT OF INTEREST}

The authors have no conflicts of interest to disclose.

\section{ORCID}

Kibong Oh: https://orcid.org/0000-0002-4661-4046

Shin Hwang: https://orcid.org/0000-0002-9045-2531

Chul-Soo Ahn: https://orcid.org/0000-0002-3844-3646

Ki-Hun Kim: https://orcid.org/0000-0002-4016-0995

Deok-Bog Moon: https://orcid.org/0000-0002-8209-3540

Tae-Yong Ha: https://orcid.org/0000-0001-9932-0212

Gi-Won Song: https://orcid.org/0000-0002-4235-0434

Dong-Hwan Jung: https://orcid.org/0000-0001-5984-023X

Seung-Mo Hong: https://orcid.org/0000-0002-8888-6007

\section{AUTHOR CONTRIBUTIONS}

Conceptualization: SH. Data curation: CSA, KHK, DBM, TYH, GWS, DHJ. Methodology: KO, SMH. Visualization: SH. Writing - original draft: KO, SH. Writing - review \& editing: $\mathrm{SH}$.

\section{REFERENCES}

1. Torzilli G, Inoue K, Midorikawa Y, Hui AM, Takayama T, Makuuchi M. Inflammatory pseudotumors of the liver: prevalence and clinical impact in surgical patients. Hepatogastroenterology 2001;48:1118-1123.

2. Horiuchi R, Uchida T, Kojima T, Shikata T. Inflammatory pseudotumor of the liver. Clinicopathologic study and review of the literature. Cancer 1990;65:1583-1590.

3. Yamamoto H, Yamaguchi H, Aishima S, Oda Y, Kohashi K, Oshiro Y, et al. Inflammatory myofibroblastic tumor versus IgG4related sclerosing disease and inflammatory pseudotumor: a comparative clinicopathologic study. Am J Surg Pathol 2009;33:13301340.

4. Zen Y, Fujii T, Sato Y, Masuda S, Nakanuma Y. Pathological classification of hepatic inflammatory pseudotumor with respect to IgG4-related disease. Mod Pathol 2007;20:884-894.

5. White JE, Chase CW, Kelley JE, Brock WB, Clark MO. Inflammatory pseudotumor of the liver associated with extrahepatic infection. South Med J 1997;90:23-29.

6. Kitajima K, Shiba H, Nojiri T, Uwagawa T, Ishida Y, Ichiba $\mathrm{N}$, et al. Intrahepatic cholangiocarcinoma mimicking hepatic inflammatory pseudotumor. J Gastrointest Surg 2007;11:398-402.

7. Ishida H, Tatsuta M, Furukawa H, Ohta H, Hashimoto K,
Hayashi N, et al. Multiple inflammatory pseudotumors mimicking liver metastasis from colon cancer: report of a case. Surg Today 2000;30:530-533.

8. Fukuya T, Honda H, Matsumata T, Kawanami T, Shimoda Y, Muranaka T, et al. Diagnosis of inflammatory pseudotumor of the liver: value of CT. AJR Am J Roentgenol 1994;163:1087-1091.

9. Park JY, Choi MS, Lim YS, Park JW, Kim SU, Min YW, et al. Clinical features, image findings, and prognosis of inflammatory pseudotumor of the liver: a multicenter experience of 45 cases. Gut Liver 2014;8:58-63.

10. Nam KJ, Kang HK, Lim JH. Inflammatory pseudotumor of the liver: CT and sonographic findings. AJR Am J Roentgenol 1996; 167:485-487.

11. Yoon KH, Ha HK, Lee JS, Suh JH, Kim MH, Kim PN, et al. Inflammatory pseudotumor of the liver in patients with recurrent pyogenic cholangitis: CT-histopathologic correlation. Radiology 1999;211:373-379.

12. Di Vita G, Soresi M, Patti R, Carroccio A, Leo P, Franco V, et al. Concomitant inflammatory pseudotumor of the liver and spleen. Liver 2001;21:217-222.

13. Vassiliadis T, Vougiouklis N, Patsiaoura K, Mpoumponaris A, Nikolaidis N, Giouleme O, et al. Inflammatory pseudotumor of the liver successfully treated with nonsteroidal anti-inflammatory drugs: a challenge diagnosis for one not so rare entity. Eur J Gastroenterol Hepatol 2007;19:1016-1020.

14. Koea JB, Broadhurst GW, Rodgers MS, McCall JL. Inflammatory pseudotumor of the liver: demographics, diagnosis, and the case for nonoperative management. J Am Coll Surg 2003;196: 226-235.

15. Yamaguchi J, Sakamoto Y, Sano T, Shimada K, Kosuge T. Spontaneous regression of inflammatory pseudotumor of the liver: report of three cases. Surg Today 2007;37:525-529.

16. Hwang S, Ha TY, Song GW, Jung DH, Ahn CS, Moon DB, et al. Quantified risk assessment for major hepatectomy via the indocyanine green clearance rate and liver volumetry combined with standard liver volume. J Gastrointest Surg 2015;19:13051314.

17. Park KS, Jang BK, Chung WJ, Cho KB, Hwang JS, Kang YN, et al. Inflammatory pseudotumor of liver--a clinical review of 15 cases. Korean J Hepatol 2006;12:429-438.

18. Ahn KS, Kang KJ, Kim YH, Lim TJ, Jung HR, Kang YN, et al. Inflammatory pseudotumors mimicking intrahepatic cholangiocarcinoma of the liver; IgG4-positivity and its clinical significance. J Hepatobiliary Pancreat Sci 2012;19:405-412.

19. Sakai T, Shiraki K, Yamamoto N, Kawakita T, Ohmori S, Itoh $\mathrm{I}$, et al. Diagnosis of inflammatory pseudotumor of the liver. Int J Mol Med 2002;10:281-285.

20. Toda K, Yasuda I, Nishigaki Y, Enya M, Yamada T, Nagura $\mathrm{K}$, et al. Inflammatory pseudotumor of the liver with primary sclerosing cholangitis. J Gastroenterol 2000;35:304-309.

21. Anthony PP. Inflammatory pseudotumour (plasma cell granuloma) of lung, liver and other organs. Histopathology 1993;23:501-503.

22. Anthony PP, Telesinghe PU. Inflammatory pseudotumour of the liver. J Clin Pathol 1986;39:761-768.

23. Shek TW, Ng IO, Chan KW. Inflammatory pseudotumor of the liver. Report of four cases and review of the literature. Am J Surg Pathol 1993;17:231-238. 